\title{
THE GOOD, THE BAD AND THE FUTURE - THE CHALLENGES, POSITIVES AND FUTURE STRATEGIES FOR HIGHER EDUCATION BLENDED TEACHING
}

\author{
Monica Ward \\ Dublin City University (Ireland)
}

\begin{abstract}
There have been many changes that have taken place in all levels of education since the Covid-19 pandemic, including at Higher Education (HE). While the swift pivot to blended teaching has been challenging and not welcomed by all, there are some positives have come about because of it and it would be good to be able to hold on to these. The challenges include moving learning materials (written, video and audio) online, engaging with students in a constructive manner and how to do assessments that are academically rigorous and have academic integrity. It is difficult for those who are used to teaching in a face-to-face environment to suddenly switch over to developing online resources and know who do this effectively and efficiently. Interacting with students online requires a different skill set than in a face-to-face environment and educators should not be expected to acquire these skills automatically. Closed-book, invigilated exams are the norm in HE institutions and ensure a level of academic integrity that has worked well for many years. It is difficult to switch from this scenario to an open-book, non-invigilated exam. It means that questions have to be re-thought to explore the students' understanding in an academic rigorous manner. Ideally, it would be good to be able to address these challenges as they mean a less positive experience for both educators and students.

The positive aspects include a more flexible approach to teaching and learning, facilitation of different modes of learning and in some cases, more interesting and authentic assessments. A more flexible approach enables students to learn at a time and place that suits them and is in keeping with the needs of the more diverse population that makes up student body in HE today. While there is a debate around learning styles, providing learning materials in a variety of formats is beneficial for all students. While it is definitely more difficult to develop open-book assessments, it is also an opportunity to do more real-world, authentic assessments that assess students' higher order skills. This moves assessment further along the Bloom's taxonomy.

This paper looks at the challenges and positives outcomes of the move to blended teaching and learning and how the challenges can be addressed, the positive aspects maintained and how a sustainable approach can be adopted to ensure that future changes to teaching are less challenging and more positive.
\end{abstract}

Keywords: Blended learning, online learning, teaching and learning, authentic assessment, future sustainability.

\section{Introduction}

Change is a constant in almost all aspects of life and Higher Education (HE) is no different. Sometimes the pace of change is slow as it can take a while for teaching, learning and assessment innovations, including blended approaches, to spread out through an institution. Lewin's change model (1947) of unfreeze, change and freeze is common in many institutions. There will always be the super-innovators (Sinclair \& Aho, 2018), innovators and early adopters (Rogers, 1962) who will use innovations more quickly than others, but there is a time lag for the early majority and late majority to deploy these innovations. The final cohort, the laggards are the last to accept and use innovations and sometimes they manage to avoid using them altogether, unless actively encouraged or made to do so. Rienties, Giesbers, Lygo-Baker, Ma, and Rees (2018) discuss teachers' use of a Virtual Learning Environment (VLE) from a technology acceptance perspective. This pattern has been in place for many years in academia. However, the Covid-19 pandemic was a sudden shock to the HE system and forced HE institutions to react rapidly and adopt new modes of teaching, learning and assessment in a very short space of time. The swift pivot to emergency online teaching brought many challenges for academics, 
students and administrators. It also brought about opportunities that could change the way things are done in HE institutions. Only time will tell which elements are retained and which ones are dropped as soon as the pandemic passes and there is the option of returning to campus and delivering face-to-face teaching. This paper looks at the challenges that arose due to the sudden shift to online teaching. It reviews the positive aspects of this shift and what future strategies might come into play in the future.

\section{Background}

While each traditional HE institution's approach to teaching, learning and assessment is different, there are some general commonalities in these approaches. Many HE institutions have an academic that teaches students in a physical location, usually a lecture hall or classroom. They have students who learn via on-campus classes, tutorial and perhaps, practical and lab sessions. Their assessment mechanism is usually a combination of continuous assessment and end of term or semester exams. The continuous assessments may be projects, assignments or other pieces of work produced by the students throughout the academic period. Some of these teaching, learning and assessment activities are paper-based, but in recent years, many HE institutions have adopted the use of VLEs for teaching and learning. At a most basic level, these may be just a repository of static documents for students to access lecture notes. At a more advanced level, it can involve the use of sophisticated quizzes, self-tests for students, discussion fora, peer review and the integration of a variety of resource types to enhance student learning. Innovators and early adopters will use the more advanced features, while the late majority will use it at a very basic level. In some cases, the laggards may manage to avoid using it altogether.

The profile of students has changed with the widening participation at higher level. In the past, the typical student would have been a full-time student, probably a young student straight out of post-primary school and from a certain socio-economic background. It was relatively easy for HE institutions to cater for this type of student with a chalk-and-talk, fully synchronous face-to-face approach. However, while this type of student still predominates, there are other types of students who do not fit this profile. There are more part-time students than before. Students have part-time jobs or other responsibilities that preclude them from attending college full time. HE institutions have more mature students and students from diverse backgrounds than ever before and the 'standard' pedagogical approaches may not work as well for these students. For example, a more andragogical approach may work better with mature students. Barrington (2004) discusses how Gardner's (1992) multiple intelligence theory can help to teach a diverse group of students.

Before the Covid-19 pandemic there was a need for change, but a lack of time (Gregory \& Lodge, 2005) and general inertia meant that there was limited impetus for real change. It is important to note that change applies to not only teaching and learning but also to assessment. Most of the commentary in the context of Covid-19 has focused on teaching and learning, but the assessment piece is challenging and must not be ignored. There are many terms used in the context of the changed teaching approaches during the Covid-19 pandemic - emergency online teaching, synchronous and asynchronous teaching, blended or hybrid teaching. In the context of this paper, emergency online teaching refers to the sudden and immediate pivot to teaching online via a video communications tool, without the usual planning, design and pedagogical supports that exist in a tradition, fully online learning environment e.g. like that of a Massively Open Online Course (MOOC). Blended or hybrid teaching refers to a mix of online synchronous and asynchronous sessions, possibly combined with some element of face-to-face teaching (Garrison \& Vaughan, 2008). Flipped classroom (Tucker, 2012) refers to a teaching approach where the instructional materials are provided to the student in advance and the synchronous classroom time can be used for more active learning approaches.

Mackey, Gilmore, Dabner, Breeze and Buckley (2012) look at the role of blended learning in a time of crisis (in their case, post earthquakes) and their findings are relevant for the current Covid-19 pandemic situation. It is somewhat ironic that they are based on New Zealand as that is the country that has dealt best with the current pandemic. They note four phases that exist in this context and although there are differences, there are many parallels Phase 1 is react, recover and redesign which aligns with the emergency pivot to online teaching. Phase 2 is the restart which was a few weeks after Phase 1 in their case but happened in parallel in the current Covid situation, Phase 3 is reconsolidation (with changes to exams) and Phase 4 was review and reflection. While there has been an element of review and reflection in the current situation, as the Covid-19 pandemic is still around, there has not been sufficient time to reflect properly on the move to blended teaching in HE institutions. 


\section{Higher education blended teaching}

There are often good reasons why people adapt slowly to change or try to avoid it altogether. In an academic context, the status quo has worked reasonably well for a long time and there is a lot of effort involved in implementing change. Academics have many claims on their time apart from teaching as they also have research and administrative duties to perform. They do not have time to explore innovations in teaching, learning and assessment and integrate them into their teaching.

\subsection{Challenges}

There were three main challenges in the move to emergency online teaching - moving learning materials (written, video and audio) online, engaging with students in a constructive manner and how to do assessments that are academically rigorous and have academic integrity. It is difficult for those who are used to teaching in a face-to-face classroom environment to develop resource for an online, asynchronous context. In the in-classroom context, a lecture might use slides with bullet points of the topics being taught but this is insufficient for asynchronous learning resources. The lecturer either has to provide more information or record a voice-over to explain the concepts to students. A further complication in the Covid-19 pandemic situation is that there was no advance planning for the switch staff had no training, no experience and no lead-in time to develop resource. The students needed the resources immediately in order to continue with their learning and know who do this effectively and efficiently.

Teaching and learning has traditionally been a social experience (Kim, 2001). The educator interacts with the students and they can ask questions if something is not clear. In a planned online learning environment, there are facilities put in place to ensure that there is a forum for student-educator interaction. In an asynchronous online learning environment, there are discussion fora that learners can use to discuss topics amongst themselves as well as ask questions. In the emergency pivot to online learning, lecturers had to learn how to use webinar apps to deliver materials synchronously. While some academics may have had experience in this area, many did not, and it was challenging enough for them to focus on teaching, without having the extra cognitive overhead of facilitating and fostering real-time interaction with students. Teaching synchronously online, while monitoring comments and questions in the chat and encouraging students to ask questions in the first place is not an easy set of skills to master in a short space of time. This is particularly true when there is no time to practice in a safe space. Lecturers are accustomed to being competent when teaching their material and removing the familiar aspects of the real classroom and replacing them with an online substitute was challenging for many academics.

Pre-Covid 19, many HE institutions would have used closed-book, invigilated exams as one of their main assessment mechanisms. There are several reasons for this - it is easy to ensure basic academic integrity, it has worked relatively well in the past and there are templates to follow rather than designing assessments from scratch. Moving from the tried and tested approach to an open-book, non-invigilated exam means that exam papers had to be completely redesigned. Lecturers had to consider how to assess students' understanding of a concept rather than asking easier questions that required students to write down memorized definitions and pieces of text. This was challenging to do in the short period available to lecturers from the start of the Covid-19 lockdown and the actual exam period.

\subsection{Positives}

There are three main positive aspects of the move to a blended approach to teaching including a more flexible approach to teaching and learning, facilitation of different modes of learning and in some cases, more interesting and authentic assessments. Flexibility is important in any learning environment. It can foster learner autonomy (Holec, 1979; Little, 1991) where learners can take charge of their own learning. Increased flexibility means that students can learn at a time and place that suits them and is in keeping with the needs of the more diverse population that makes up student body in HE today. This element of flexibility was particularly important in the early stages of the Covid-19 pandemic when students (and staff alike) had to contend with caring responsibilities, health issues and internet connectivity issues.

The concept of learning styles has been around for some time. While there are many different learning styles models (Hawk \& Shah, 2008) they generally assume that people differ in how they learn. There is a debate around learning styles and to whether or not they actually exist (Pashler, McDaniel, Rohrer \& Bjork, 2009). However, one positive outcome of the Covid-19 blended approach is that students have access to materials and topics in a variety of formats. With the flipped classroom model, students can use whichever resources work best for them, before coming into the online or face-to-face classroom. The provision of learning resources in different formats is beneficial for all students, regardless of their learning preferences. 
Not too many people like assessments. In general, lecturers do not like setting or marking exams. Most students do not like taking exams. Assessments should be learner centered and educative (Wiggins, 1998) but, in many HE institutions across the world, a terminal exam is the most common way to do summative assessment (Knight, 2002). Designing and developing open-book, non-invigilated assessments is definitely more difficult than for closed-book, invigilated exams. For example, instead of asking "What is the definition of $x$ ?", academics have to ask a more probing question exploring a student's knowledge of $\mathrm{x}$, as the student could easily just copy or paraphrase a definition form an available source. While this is more demanding, it is also an opportunity to do more real-world, authentic assessments that assess students' higher order skills. This moves assessment further along the Bloom's taxonomy (Bloom, 1956) and gives better insight into a student's knowledge, skills and mastery of particular concepts.

\subsection{Future strategies}

There are several different observations from a strategic point of view that must be considered for the future direction of travel for HE institutions in the blended area. It was a testimony to the competence and adaptability of staff that they were able to pivot so quickly to online teaching. While it may not have been the rounded, polished experience of a well-planned and designed learning environment, they did manage to teach, the students managed to learn and assessments were carried out successfully. Even those who were technophobic before the Covid-19 pandemic managed to get to grips with a blended learning approach. This indicates that changes aimed at incorporating educational technologies into teaching, learning and assessment can be made if there is the will or the need to implement them. Sometimes it takes a major incident or impetus to give energy and purpose to the change mechanisms within an institution and once people are on the blended path, it is easier to keep them there.

The need for planning for future possible problems has been clearly heighted by the Covid-19 pandemic in all societal domains, including HE. There were very few institutions who were ready or had plans for such an event, although some institutions had started planning a few weeks in advance as they anticipated that a lockdown might occur. Hopefully, there will not be an event like Covid-19 again in the future, but it is not impossible. There are twin planning needs of having the right technological infrastructure but also the right pedagogical infrastructure in HE institutions. This pedagogical infrastructure includes having a knowledge learning enhancement unit (or equivalent), regular, focused Continuous Professional Development (CPD) opportunities for staff and that they are encouraged to attend. They should have the opportunity to learn about the research behind blended teaching and learning approaches and have the opportunity to experiment with them in a safe environment before actually using them in their own teaching. As with their students, the information should be designed with the target learner in mind with enough theory to demonstrate the research, but also a practical element so that academics can see how they can actually use the approaches. A co-creation approach should be adopted to ensure that CPD opportunities are leveraged correctly. Peer learning is very powerful in this context, as when academics can see that their peers and colleagues have used something successfully, they will feel more comfortable and confident using it themselves.

\section{Discussion and conclusion}

While experiences of academics in different countries have varied during the Covid-19 pandemic, there are some common elements. One is the lack of preparedness for such an event (Goedegebuure and Meek, 2021). HE institutions should have risk management plans and it is clear that most of them were under-prepared for a crisis of the magnitude of Covid-19. However, there are also lower level risks that are often overlooked by senior management. In some HE institutions, if an academic is unable to deliver a module, there is often a scramble to find someone to cover for that person. There is very little backup coverage. Goedegebuure and Meek (2021) also note that frustration, isolation and reflection were key aspects of staff's professional experience of the Covid-19 pandemic.

As blended learning becomes more mainstream in HE institutions, it is important to ensure that educators and students are comfortable and competent in this area. There should be basic onboarding resources for academics and learners that does not assume any prior knowledge. There are specific skills that are required to be a successful online and blended lecturer and to be a successful online a blended learner and it is important. There should be some mechanism for continual learning in this space, as knowledge in the blended learning space increases, academics who have to teach in that space should be aware of that knowledge to improve their own blended teaching skills. There is still a piece of work to be done on assessment in the blended space, as academics aim to ensure academic integrity in an open-book non-invigilated context. There will be a variety of approaches ranging from proctoring, to interactive oral examinations (Sotiriadou, Logan, Daly, \& Guest, 2020) and re-designed contextualized exams. Academics and students alike will need upskilling if these approaches are adopted. 
Post-Covid 19, HE institutions will not go back to being like they were before the pandemic. Certainly, many of them will return to the traditional face-to-face mode of teaching and this will be welcomed by many. However, now that academics and students have experienced be benefits that come with a blended approach, they will look to hold on to them in the future. Who would not want the benefit of having (extra) online resources to help with their learning? The flipped classroom has been around for some time and facilitates a more active learning paradigm for students. Although the level of preparation is initially higher for this approach, it yields benefits in the long run. It also requires a shift in an academic's perception of their role - less 'sage on the stage' and more 'guide on the side' and this might take some time to bed down. The flexibility available with a blended approach is something that students will not want to relinquish.

In summary, there are and there will continue to be many challenges in the rollout of blended learning in HE institutions. These challenges will change over time as general awareness and knowledge increases in the wider academic community of staff students and administrators. Just as those who are vaccine hesitant must be treated with respect and encouraged to get vaccinated, so too must those who are blended hesitant be treated with respect and their concerns addressed. Those who are familiar with the blended learning approach will already know the benefits but pre-Covid may have had difficulties persuading others to adopt (at least some elements of) the approach. The changes that have occurred in one year due to Covid-19 could possibly have taken 10 years under normal circumstances. Not everyone will stick with blended, but there is now a much wider community that will continue to drive forward the approach and continue to improve things in the blended arena.

\section{References}

Barrington, E. (2004). Teaching to student diversity in higher education: How multiple intelligence theory can help. Teaching in Higher Education, 9(4), 421-434.

Bloom, B. S. (1956). Taxonomy of educational objectives: The classification of educational goals. Cognitive domain.

Gardner, H. (1992). Multiple intelligences (Vol. 5, p. 56). Minnesota Center for Arts Education.

Garrison, D. R., \& Vaughan, N. D. (2008). Blended learning in higher education: Framework, principles, and guidelines. John Wiley \& Sons.

Gregory, M. S. J., \& Lodge, J. M. (2015). Academic workload: the silent barrier to the implementation of technology-enhanced learning strategies in higher education. Distance education, 36(2), 210-230.

Hawk, T. F., \& Shah, A. J. (2007). Using learning style instruments to enhance student learning. Decision Sciences Journal of Innovative Education, 5(1), 1-19.

Holec, H. (1979). Autonomy and foreign language learning.

Kim, B. (2001). Social constructivism. Emerging perspectives on learning, teaching, and technology, $1(1), 16$.

Knight, P. T. (2002). Summative assessment in higher education: practices in disarray. Studies in higher Education, 27(3), 275-286.

Lewin, K. (1947). Change management model.

Little, D. (1991). Learner autonomy. Dublin, 86, 11.

Mackey, J., Gilmore, F., Dabner, N., Breeze, D., \& Buckley, P. (2012). Blended learning for academic resilience in times of disaster or crisis.

Pashler, H., McDaniel, M., Rohrer, D., \& Bjork, R. (2008). Learning styles: Concepts and evidence. Psychological science in the public interest, 9(3), 105-119.

Rienties, B., Giesbers, B., Lygo-Baker, S., Ma, H. W. S., \& Rees, R. (2016). Why some teachers easily learn to use a new virtual learning environment: a technology acceptance perspective. Interactive Learning Environments, 24(3), 539-552.

Sinclair, J., \& Aho, A. M. (2018). Experts on super innovators: understanding staff adoption of learning management systems. Higher Education Research \& Development, 37(1), 158-172.

Sotiriadou, P., Logan, D., Daly, A., \& Guest, R. (2020). The role of authentic assessment to preserve academic integrity and promote skill development and employability. Studies in Higher Education, 45(11), 2132-2148.

Tucker, B. (2012). The flipped classroom. Education next, 12(1), 82-83.

Wiggins, G. (1998). Educative Assessment. Designing Assessments to Inform and Improve Student Performance. Jossey-Bass Publishers, 350 Sansome Street, San Francisco, CA 94104. 